\title{
Coronary events and exposure to environmental tobacco smoke: a case-control study from Australia and New Zealand
}

Patrick McElduff, Annette J Dobson, Rod Jackson, Robert Beaglehole, Richard F Heller, Roy Lay-Yee

\begin{abstract}
Objectives-To estimate the relative risk of coronary heart disease (CHD) associated with exposure to environmental tobacco smoke (ETS).

Design-Population-based case-control study.

Subjects-Cases were 953 people identified in a population register of coronary events, and controls were 3189 participants in independent community-based risk factor prevalence surveys from the same study populations.

Setting-Newcastle, Australia and Auckland, New Zealand.

Main outcome measures-Acute myocardial infarction or coronary death.

Results-After adjusting for the effects of age, education, history of heart disease, and body mass index, women had a statistically significant increased risk of a coronary event associated with exposure to ETS (relative risk $(R R)=1.99 ; 95 \%$ confidence interval $(\mathrm{CI})=1.40-2.81)$. There was little statistical evidence of increased risk found in men $(R R=1.02,95 \% \mathrm{CI}=$ 0.81-1.28).

Conclusion-Our study found evidence for the adverse effects of exposure to ETS on risk of coronary heart disease among women, especially at home. For men the issue is unclear according to the data from our study. Additional studies with detailed information on possible confounders and adequate statistical power are needed. Most importantly, they should use methods for measuring exposure to ETS that are sufficiently accurate to permit the investigation of dose-response relationships.
\end{abstract}

(Tobacco Control 1998;7:41-46)

Keywords: coronary heart disease, environmental tobacco smoke, World Health Organisation MONICA project

\section{Introduction}

The number of epidemiological studies finding an adverse effect of environmental tobacco smoke (ETS) on risk of coronary heart disease (CHD) is increasing, and experimental studies suggest that these adverse effects are biologically plausible. In a review of the literature in 1992, Steenland ${ }^{1}$ examined six cohort and three case-control studies and concluded that the relative risk of CHD due to exposure to ETS was 1.29 for men and 1.22 for women in the American population (confidence intervals were not given). Glantz and Parmley ${ }^{2}$ described in detail the biological effects of ETS on the coronary system, and assessed the evidence from epidemiological studies, including three that had been published since Steenland's review. From 12 studies, the estimated relative risk of CHD was 1.2 (95\% confidence interval $(\mathrm{CI})=1.1$ to 1.4$)$, but many of the studies had very few cases and failed to take into account confounding factors. Therefore there is a need for large epidemiological studies that can provide good control for the possible effects of confounding.

Using data collected in New Zealand and Australia, we present the results of a case-control study to estimate the relative risk of CHD associated with exposure to ETS after adjustment for major confounding factors. The case-control study by Dobson et $\mathrm{al}^{3}$, which was included in both the reviews mentioned above, used the 1988/89 Newcastle data that have also been included in this paper.

\section{Methods}

This study is a product of the World Health Organisation (WHO) MONICA Project which has monitored trends and determinants of cardiovascular disease in well-defined populations in more than 20 countries over 10 years. Two of these populations are people aged 35-69 in Newcastle, Australia and people aged 35-64 in Auckland, New Zealand.

CASES AND CONTROLS

The WHO MONICA Project involved registration of all suspected coronary events occurring in the study populations through continuous surveillance of all hospitals and scrutiny of all deaths certificates. Cases were defined as those who had coronary events that satisfied the criteria for non-fatal definite myocardial infarction (MI), fatal definite MI, fatal possible MI, or unclassifiable coronary death. ${ }^{4}$ In both centres information on non-fatal cases was obtained by interviewing patients while they were still in hospital to obtain information on symptoms, medical history, and other variables. Cardiac enzyme results were extracted from hospital notes and electrocardiographs (ECGs) were copied and subsequently coded according to the Minnesota code. Details of fatal cases were obtained from death certificates, from postmortem records, and from doctors, relatives, or other informants. 
Information on exposure to ETS was only collected from cases in the periods 1988/89 and 1992-94 in Newcastle and 1986-88 in Auckland, coinciding approximately with the community-based risk factor prevalence studies.

Controls were participants in risk factor prevalence studies also conducted as part of the WHO MONICA Project. In Newcastle the first risk factor study used for this paper was conducted in June-December 1988 and JuneNovember 1989, and the second was conducted in June-December 1994. In Auckland the risk factor study was conducted between February 1986 and January 1988. There were 86764 men and 87164 women aged between 35 and 69 years in the Newcastle study population at the 1991 census and 171260 men and 176380 women aged 35-64 years in the study population in Auckland at the 1986 census.

For both risk factor studies in Newcastle, a stratified random sample of the study population was selected from the electoral roll, with the sampling fraction being greater for the older age strata. (In Australia and New Zealand registration on the electoral roll is compulsory for most of the population and more than $95 \%$ of the eligible people are enrolled). People chosen for the sample were invited to attend study centres to complete a self-administered questionnaire and to have physical measurements made. Extensive systems of reminders and follow up were used to encourage participation. In Auckland, subjects for the risk factor study were randomly selected from the electoral roll but, unlike Newcastle, they were group-matched on age and sex. Case-control ratios of $1: 1.5$ in men and 1:3 in women were planned. Controls attended a study centre where they had body measurements taken and completed an interviewer-administered questionnaire. The response rate was $63 \%$ for Newcastle in 1988 / $89,64 \%$ for Newcastle in 1994 , and $83 \%$ for the Auckland survey. In Newcastle there is some evidence that non-participants in the survey were more likely than participants to be cigarette smokers and so would have been less likely to meet the inclusion criteria for this study. ${ }^{5}$

\section{DEFINITIONS}

In both centres questions on smoking status allowed us to categorise former smokers by time since they quit smoking. People were only included in the analysis presented here if they had never smoked cigarettes or had stopped smoking cigarettes at least 10 years before the date of interview and were not current smokers of pipes, cigars, or cigarillos. This resulted in the inclusion of $36 \%, 35 \%$, and $27 \%$ of cases and $62 \%, 66 \%$, and $70 \%$ of controls for Auckland, Newcastle 1988/89, and Newcastle 1992-94, respectively, because cases were much more likely than controls to be current smokers.

For the three data sets, different questions were used to ascertain exposure to ETS, but within each of the studies the questions put to cases and controls were identical. In Auckland the questions were: "How many members of your household smoke cigarettes at home in your presence?" and "Do any workers smoke indoors in the same room where you work?". If the answer to the first question was greater than zero or the answer to the second question was "yes", then the person was deemed to have been exposed to ETS. In 1988/89 in Newcastle the questions were: "Are you exposed to

Table 1 Crude odds ratios and 95\% confidence intervals for factors associated with risk of coronary events in Newcastle, Australia and Auckland, New Zealand

\begin{tabular}{|c|c|c|c|c|c|c|c|c|c|c|c|c|}
\hline & \multicolumn{4}{|c|}{ Newcastle 1988/89 } & \multicolumn{4}{|c|}{ Newcastle 1992-94 } & \multicolumn{4}{|c|}{ Auckland 1986-88 } \\
\hline & $\begin{array}{l}\text { Cases } \\
(n=367) \\
(\%)\end{array}$ & $\begin{array}{l}\text { Controls } \\
(n=1081) \\
(\%)\end{array}$ & $O R$ & $95 \% C I$ & $\begin{array}{l}\text { Cases } \\
(n=283) \\
(\%)\end{array}$ & $\begin{array}{l}\text { Controls } \\
(n=1171) \\
(\%)\end{array}$ & $O R$ & $95 \% C I$ & $\begin{array}{l}\text { Cases } \\
(n=303) \\
(\%)\end{array}$ & $\begin{array}{l}\text { Controls } \\
(n=937) \\
(\%)\end{array}$ & $O R$ & $95 \% C I$ \\
\hline \multicolumn{13}{|l|}{ Passive smoking } \\
\hline No & 72.2 & 70.3 & 1.00 & & 70.3 & 72.8 & 1.00 & & 72.3 & 78.2 & 1.00 & \\
\hline Yes & 27.8 & 29.7 & 0.91 & $0.70-1.19$ & 29.7 & 27.2 & 1.13 & $0.85-1.50$ & 27.7 & 21.8 & 1.38 & $1.03-1.85$ \\
\hline \multicolumn{13}{|l|}{ Sex } \\
\hline Male & 70.3 & 44.3 & 1.00 & & 70.0 & 46.5 & 1.00 & & 75.9 & 57.1 & 1.00 & \\
\hline Female & 29.7 & 55.7 & 0.34 & $0.26-0.43$ & 30.0 & 53.5 & 0.37 & $0.28-0.49$ & 24.1 & 42.9 & 0.42 & $0.32-0.57$ \\
\hline \multicolumn{13}{|l|}{ Age group } \\
\hline $35-49$ & 6.3 & 34.5 & 0.10 & $0.06-0.15$ & 7.9 & 30.7 & 0.18 & $0.11-0.30$ & 19.8 & 28.4 & 0.42 & $0.30-0.60$ \\
\hline $50-54$ & 7.9 & 12.6 & 0.42 & $0.26-0.66$ & 9.2 & 12.9 & 0.51 & $0.31-0.84$ & 15.8 & 19.9 & 0.49 & $0.34-0.72$ \\
\hline $55-59$ & 14.4 & 13.9 & 0.69 & $0.47-1.02$ & 13.4 & 12.8 & 0.75 & $0.49-1.17$ & 22.1 & 25.7 & 0.53 & $0.38-0.75$ \\
\hline $60-64$ & 29.4 & 19.5 & 1.00 & & 28.6 & 20.6 & 1.00 & & 42.2 & 26.0 & 1.00 & \\
\hline $65-69$ & 42.0 & 19.5 & 1.43 & $1.04-1.95$ & 41.0 & 23.0 & 1.28 & $0.92-1.80$ & & & & \\
\hline \multicolumn{13}{|l|}{ History of CHD } \\
\hline No & 54.8 & 91.6 & 1.00 & & 58.3 & 91.1 & 1.00 & & 56.1 & 93.9 & 1.00 & \\
\hline Yes & 45.2 & 8.4 & 8.98 & $6.67-12.09$ & 41.7 & 8.9 & 7.34 & $5.38-10.01$ & 43.9 & 6.1 & $\begin{array}{l}12.0 \\
8\end{array}$ & $8.50-17.16$ \\
\hline \multicolumn{13}{|l|}{ Education } \\
\hline $\begin{array}{l}\text { Primary or high } \\
\text { school }\end{array}$ & 79.3 & 71.0 & 1.00 & & 71.4 & 63.6 & 1.00 & & 52.1 & 35.2 & 1.00 & \\
\hline Technical college & 12.3 & 17.8 & 0.62 & $0.43-0.88$ & 23.3 & 23.5 & 0.89 & $0.65-1.21$ & 25.1 & 22.5 & 0.75 & $0.55-1.03$ \\
\hline University & 5.7 & 11.3 & 0.45 & $0.28-0.73$ & 4.2 & 12.8 & 0.30 & $0.16-0.54$ & 22.8 & 29.0 & 0.53 & $0.38-0.73$ \\
\hline Unknown & 2.7 & 0.0 & & & 1.1 & 0.1 & & & & & & \\
\hline \multicolumn{13}{|l|}{ Body mass index } \\
\hline$<25$ & 39.2 & 34.3 & 1.00 & & 33.2 & 31.1 & 1.00 & & 45.5 & 58.3 & 1.00 & \\
\hline $25-30$ & 39.8 & 45.4 & 0.77 & $0.59-1.00$ & 40.3 & 43.9 & 0.86 & $0.63-1.16$ & 38.6 & 33.1 & 1.49 & $1.13-1.98$ \\
\hline$>30$ & 16.3 & 19.7 & 0.73 & $0.52-1.02$ & 23.7 & 25.0 & 0.89 & $0.64-1.22$ & 15.9 & 8.1 & 2.50 & $1.66-3.75$ \\
\hline Unknown & 4.6 & 0.6 & & & 2.8 & 0.0 & & & 0.0 & 0.5 & & \\
\hline
\end{tabular}

$\mathrm{CHD}=$ coronary heart disease.

$\mathrm{OR}=$ odds ratios; $\mathrm{CI}=$ confidence intervals 
Table 2 Crude odds ratios and 95\% confidence intervals for exposure to environmental tobacco smoke for potential covariates for Newcastle, Australia and Auckland, New Zealand

\begin{tabular}{|c|c|c|c|c|c|c|c|c|c|c|c|c|}
\hline & \multicolumn{4}{|c|}{ Newcastle 1988/89 } & \multicolumn{4}{|c|}{ Newcastle 1992-94 } & \multicolumn{4}{|c|}{ Auckland 1986-88 } \\
\hline & \multicolumn{2}{|l|}{ Cases } & \multicolumn{2}{|c|}{ Controls } & \multicolumn{2}{|l|}{ Cases } & \multicolumn{2}{|c|}{ Controls } & \multicolumn{2}{|l|}{ Cases } & \multicolumn{2}{|c|}{ Controls } \\
\hline & $O R$ & $95 \% C I$ & $O R$ & $95 \% C I$ & $O R$ & $95 \% C I$ & $O R$ & $95 \% C I$ & $O R$ & $95 \% C I$ & $O R$ & $95 \% C I$ \\
\hline \multicolumn{13}{|l|}{ Sex } \\
\hline Male & 0.84 & $0.51-1.38$ & 1.21 & $0.93-1.58$ & 0.64 & $0.37-1.10$ & 1.50 & $1.16-1.95$ & 1.66 & $0.88-3.12$ & 1.76 & $1.27-2.45$ \\
\hline Female & 1.00 & & 1.00 & & 1.00 & & 1.00 & & 1.00 & & 1.00 & \\
\hline \multicolumn{13}{|l|}{ Age group } \\
\hline $35-49$ & 3.54 & $1.39-8.98$ & 2.87 & $1.91-4.30$ & 1.38 & $0.53-3.64$ & 1.12 & $0.78-1.61$ & 2.12 & $1.04-4.29$ & 1.62 & $1.04-2.51$ \\
\hline $50-54$ & 1.02 & $0.42-2.48$ & 2.56 & $1.57-4.19$ & 1.25 & $0.50-3.12$ & 0.99 & $0.63-1.56$ & 2.28 & $1.08-4.84$ & 1.72 & $1.08-2.75$ \\
\hline $55-59$ & 1.49 & $0.75-2.96$ & 2.63 & $1.63-4.25$ & 0.92 & $0.40-2.11$ & 0.84 & $0.52-1.34$ & 2.90 & $1.49-5.64$ & 1.36 & $0.86-2.15$ \\
\hline $60-64$ & 1.00 & & 1.00 & & 1.00 & & 1.00 & & 1.00 & & 1.00 & \\
\hline $65-69$ & 0.44 & $0.24-0.80$ & 0.70 & $0.42-1.19$ & 0.58 & $0.31-1.09$ & 0.91 & $0.62-1.36$ & & & & \\
\hline \multicolumn{13}{|l|}{ History of CHD } \\
\hline No & 1.00 & & 1.00 & & 1.00 & & 1.00 & & 1.00 & & 1.00 & \\
\hline Yes & 0.84 & $0.53-1.34$ & 0.64 & $0.39-108$ & 0.65 & $0.38-1.11$ & 0.93 & $0.59-1.47$ & 0.77 & $0.46-1.29$ & 1.57 & $0.87-2.84$ \\
\hline \multicolumn{13}{|l|}{ Education } \\
\hline $\begin{array}{l}\text { Primary or high } \\
\text { school }\end{array}$ & 1.00 & & 1.00 & & 1.00 & & 1.00 & & 1.00 & & 1.00 & \\
\hline Technical college & 0.70 & $0.33-1.49$ & 1.09 & $0.78-1.52$ & 0.73 & $0.39-1.37$ & 0.74 & $0.54-1.02$ & 1.52 & $0.84-2.73$ & 1.31 & $0.90-1.91$ \\
\hline University & 0.58 & $0.19-1.77$ & 0.72 & $0.47-1.12$ & 0.19 & $0.02-1.52$ & 0.46 & $0.29-0.73$ & 0.77 & $0.39-1.50$ & 0.90 & $0.62-1.31$ \\
\hline \multicolumn{13}{|l|}{ High blood pressure } \\
\hline No & 1.00 & & 1.00 & & 1.00 & & 1.00 & & & & & \\
\hline Yes & 0.89 & $0.56-1.42$ & 0.86 & $0.65-1.13$ & 1.23 & $0.72-2.10$ & 1.16 & $0.89-1.51$ & & & & \\
\hline \multicolumn{13}{|c|}{ High blood cholesterol } \\
\hline No & 1.00 & & 1.00 & & 1.00 & & 1.00 & & 1.00 & & & \\
\hline Yes & 1.05 & $0.66-1.67$ & 0.72 & $0.53-0.97$ & 1.01 & $0.60-1.71$ & 0.99 & $0.74-1.31$ & & & & \\
\hline \multicolumn{13}{|l|}{ Body mass index } \\
\hline$<25$ & 1.00 & & 1.00 & & 1.00 & & 1.00 & & 1.00 & & 1.00 & \\
\hline $25-30$ & 1.53 & $0.82-2.89$ & 0.90 & $0.67-1.21$ & 1.14 & $0.61-2.11$ & 1.47 & $1.07-2.00$ & 1.31 & $0.75-2.27$ & 1.36 & $0.98-1.91$ \\
\hline$>30$ & 1.52 & $0.69-3.36$ & 0.84 & $0.57-1.23$ & 1.63 & $0.82-3.22$ & 1.45 & $1.02-2.06$ & 1.39 & $0.67-2.86$ & 1.71 & $1.00-2.93$ \\
\hline Unknown & 1.38 & $0.74-2.60$ & 2.21 & $0.44-11.12$ & 2.92 & $0.68-12.57$ & & & & & & \\
\hline
\end{tabular}

$\mathrm{CHD}=$ coronary heart disease

$\mathrm{OR}=$ odds ratios $\mathrm{CI}=$ confidence intervals

tobacco smoke at home?" and "If you work outside the home, are you exposed to tobacco smoke at work?". If the answer to either of these questions was "yes", then the person was deemed to have been exposed to ETS. For 1992-94 in Newcastle the subjects were asked: "For how many hours on average each day are you closely exposed to other peoples' tobacco smoke?". If the answer to this question was greater than zero, then the person was deemed to have been exposed to ETS.

Age was categorised into five-year groups from 35-39 to 65-69 for Newcastle and from 35-39 to 60-64 for Auckland. In Auckland, data were not collected for those aged 65-69. There were few cases in the categories 35-39, $40-44$, and $45-49$ years so they were combined to form one category of 35-49 years. Education was used as an indicator of socioeconomic status. It was analysed in three categories: primary or high school; technical college; and university or professional institution (college of advanced education). Subjects were deemed to have had a history of heart disease if they answered "yes" to either of the following questions: "Have you ever been told you have had a heart attack/myocardial infarction?" or "Have you ever been told you have angina?". Body mass index (BMI) was calculated by dividing weight in kilograms by the square of height in metres. In Newcastle subjects were deemed to have high blood pressure if they answered "yes" to the question: "Have you ever been told by a doctor or other medical person that you have high blood pressure?". A similar question was used to ascertain hypercholesterolaemia; information on history of high blood cholesterol and history of high blood pressure was not available in Auckland.

ANALYSIS

The initial exploratory analysis involved univariate analysis of factors associated with risk of a major coronary event separately for each centre. Logistic regression was used to estimate crude odds ratios for the risk of suffering a major coronary event associated with passive smoking, sex, age, education, history of heart disease and BMI. Logistic regression was also used to estimate crude odds ratios for exposure to ETS associated with each of the potentially confounding variable of age, sex, education, history of heart disease, and BMI in both centres, as well as for the association between exposure to ETS and history of high blood pressure and history of high blood cholesterol in Newcastle. To determine if the results for the three data sets were similar, we compared the crude odds ratios for all variables. This analysis showed that the data sets were fairly homogeneous, so the data were combined and the analysis performed on all the data together.

To test if there was a difference in risk of a coronary event associated with exposure to ETS, unconditional logistic regression was used to calculate crude odds ratios and 95\% confidence intervals. Odds ratios were also calculated after adjusting for the effects of age, education, and history of heart disease. There was approximately $4 \%$ missing data on height or weight measurements in Newcastle; therefore, the results are presented with and without adjusting for BMI. All analyses were performed separately for men and women. An 
Table 3 Adjusted odds ratios and 95\% confidence intervals for risk of a major coronary event associated with exposure to environmental tobacco smoke

\begin{tabular}{|c|c|c|c|c|c|c|c|c|c|}
\hline Time and place & & Cases & Controls & $\begin{array}{l}\text { Crude } \\
\text { OR }\end{array}$ & $95 \% C I$ & Adjusted $O R^{\star}$ & $95 \% C I$ & Adjusted OR† & $95 \% C I$ \\
\hline \multicolumn{10}{|l|}{ Male } \\
\hline \multirow[t]{2}{*}{ All data } & Exposed & 191 & 463 & 0.91 & $0.75-1.11$ & 0.98 & $0.78-1.23$ & 1.02 & 0.811 .28 \\
\hline & Not exposed & 495 & 1096 & & & & & & \\
\hline Newcastle & Exposed & 69 & 153 & 0.78 & $0.56-1.09$ & 1.04 & $0.70-1.55$ & 1.09 & $0.72-1.63$ \\
\hline $1988 / 89$ & Not exposed & 189 & 326 & & & & & & \\
\hline Newcastle & Exposed & 53 & 172 & 0.79 & $0.55-1.14$ & 0.78 & $0.53-1.15$ & 0.82 & $0.55-1.22$ \\
\hline $1992-94$ & Not exposed & 145 & 373 & & & & & & \\
\hline Auckland & Exposed & 69 & 138 & 1.23 & $0.88-1.74$ & 1.19 & $0.80-1.77$ & 1.14 & $0.76-1.70$ \\
\hline 1986-88 & Not exposed & 161 & 397 & & & & & & \\
\hline \multicolumn{10}{|l|}{ Female } \\
\hline \multirow[t]{2}{*}{ All data } & Exposed & 79 & 381 & 1.39 & $1.04-1.86$ & 2.05 & $1.46-2.87$ & 1.99 & $1.40-2.81$ \\
\hline & Not exposed & 188 & 1249 & & & & & & \\
\hline Newcastle & Exposed & 33 & 168 & 1.12 & $0.72-1.75$ & 2.11 & $1.23-3.63$ & 2.24 & $1.28-3.91$ \\
\hline $1988 / 89$ & Not exposed & 76 & 434 & & & & & & \\
\hline Newcastle & Exposed & 31 & 147 & 1.87 & $1.16-3.02$ & 2.42 & $1.36-4.28$ & 2.15 & $1.18-3.92$ \\
\hline 1992-94 & Not exposed & 54 & 479 & & & & & & \\
\hline Auckland & Exposed & 15 & 66 & 1.32 & $0.70-2.46$ & 1.63 & $0.80-3.31$ & 1.56 & $0.76-3.20$ \\
\hline $1986-88$ & Not exposed & 58 & 336 & & & & & & \\
\hline
\end{tabular}

*Adjusted for age, education, and history.

†Adjusted for age, education, history, and body mass index.

$\mathrm{OR}=$ odds ratios; $\mathrm{CI}=$ confidence intervals .

indicator variable was used for centre in the combined analysis of all three data sets.

\section{Results}

There were 953 cases (670 non-fatal definite AMIs and 283 coronary deaths) and 3189 controls who met the inclusion criteria (that is, were never-smokers or had last smoked at least 10 years ago). The crude odds ratios for coronary events for the three data sets in relation to exposure to ETS, sex, age, and education are shown in table 1. For passive smoking the crude odds ratios were $0.91,1.13$, and 1.38 for the two Newcastle and the Auckland studies, respectively. Controls in Newcastle were selected by age-stratified random sampling, but in Auckland controls were matched on age; therefore, the apparent difference in the age effect between the centres was due to the different study designs. In Auckland, cases and controls tended to have lower BMIs than cases and controls in Newcastle. The crude odds ratios associated with higher BMI were substantial in Auckland but in Newcastle there appeared to be no effect.

There was stronger evidence of potential confounding effects for sex and age on the association between coronary events and passive smoking than for education, history of heart disease, or BMI (table 2). In each control group there was higher prevalence of exposure to ETS for men than women and more exposure to ETS in younger than older people, although the age effect was not apparent in Newcastle in 1994. Higher education level was associated with less exposure to ETS in Newcastle. There was an association between history of high blood cholesterol and exposure to ETS in the control group in Newcastle in 1992-94 but adjustment for history of high cholesterol in the logistic regression made little difference to the odds ratios (unchanged for men and 2.18 to 2.10 for women). There was no evidence of an association between passive smoking and history of high blood pressure in the Newcastle data.

Table 3 gives the odds ratios for coronary events among people exposed to ETS compared with those not exposed, separately for men and women. In all three data sets women had a higher risk than men. In both time periods, data for Newcastle showed a statistically significant higher risk of coronary events for women exposed to ETS. There was also a higher risk of coronary events for women in Auckland, but it was not statistically significant. The adjusted odds ratio for women using all three data sets was 1.99 with a $95 \%$ confidence interval of 1.40 to 2.81 . The situation for men was different; all three data sets showed no statistically significant increase in risk associated with passive smoking. The overall odds ratio was 1.02 with a $95 \%$ confidence interval of $0.81-1.28$.

In 1988/89 in Newcastle and in Auckland exposure to ETS was specified separately as exposure at home and exposure at work. In these periods, women who were exposed to ETS were almost twice as likely as men who were exposed, to be exposed at home only ( $59 \%$ vs $31 \%$ in Newcastle and $32 \%$ vs $19 \%$ in Auckland). When the risks of a major coronary event due to exposure at work and exposure at home were estimated separately, there were substantial differences between men and women. For men the risks of a major coronary event associated with exposure to ETS at home and at work were not statistically different $(\mathrm{OR}=0.88,95 \% \mathrm{CI}=0.59-1.30$ vs $\mathrm{OR}=$ $1.31,95 \%$ CI $=0.95-1.80)$. For women the risk was greater at home $(\mathrm{OR}=2.52,95 \%$ $\mathrm{CI}=1.57-4.06$ vs $\mathrm{OR}=0.58,95 \% \quad \mathrm{CI}=$ $0.27-1.24)$.

\section{Discussion}

There have been a number of studies published on the relationship between passive smoking and coronary heart disease, but most of these have death as the main outcome. A report from the American Nurses Health Study published in 1997 is one of the few to examine the association between exposure to ETS and non-fatal, as well as fatal, coronary heart disease. Based on 152 coronary events in a cohort study of more than 32000 women, non-smokers who were regularly exposed to 
ETS at home or work were found to have a relative risk of $1.91(95 \% \mathrm{CI}=1.11-3.28){ }^{6}$ Our study involved 686 cases of AMI or coronary death among men and 267 cases among women in two different countries at three time periods. Cases were defined according to the strict criteria of the WHO MONICA project, and within each of the study populations there was almost complete case ascertainment. Controls were obtained from random samples of the same study populations during the same time periods. Therefore the strengths of this study are high power, high ascertainment of cases, and low chance of selection bias.

Several case-control studies have shown that the risk of AMI due to smoking decreases to that of a never-smoker five years after quitting smoking. ${ }^{58}$ In this study we included never-smokers and former smokers who had quit smoking at least 10 years ago. This cautious approach ensured that all those included in the study were likely to have the same baseline risk of AMI due to smoking status.

We found a statistically significant increased risk for women exposed to ETS similar to that found by both $\mathrm{He}$ et $\mathrm{al}^{9}$ and Kawachi et al, ${ }^{6}$ but no increased risk for men. Possible reasons for this are: (a) women are exposed to higher doses of ETS; (b) women are more aware of their exposure to ETS; (c) women have a greater adverse response to ETS; and (d) this is a chance finding.

Estimates based on data collected as part of the Australian Bureau of Statistics National Health Survey in 1989-90 indicate that non-smoking women were almost twice as likely as non-smoking men to be married to a current smoker. ${ }^{10}$ Also, those men who were current smokers married to non-smoking women were more than twice as likely to be heavy smokers (smoking more than 20 cigarettes per day) than women who were current smokers married to non-smoking men. The CHD event rate in smokers increases with dose $^{11}$ and it is plausible that the risk for passive smokers increases with dose as well. Therefore a likely reason women have a greater risk is that they are subjected to higher levels of ETS at home.

The general limitations of studies of the association between passive smoking and coronary heart disease are the potential for confounding, the difficulty in assessing exposure, and the small effect size.

For a variable to confound the relationship between passive smoking and coronary heart disease, it must be associated with passive smoking and risk of a coronary event. Therefore factors that have been shown to be associated with risk of a coronary event, such as hypertension, hypercholesterolaemia, history of heart disease, BMI, age, sex, socioeconomic status, and smoking status, can only affect the relationship between passive smoking and coronary heart disease, if they are also associated with passive smoking. We excluded current smokers and those who had quit within the past 10 years, the analyses were performed separately for men and women, and we adjusted for age, history of heart disease, BMI, and education (as a marker for socioeconomic status). Using the Newcastle data we were also able to investigate the effect of adjusting for self-reported history of hypertension and hypercholesterolaemia, and found no substantial effect on the risk of a major coronary event associated with passive smoking.

Adjusted odds ratios were considerably higher than crude odds ratios only for Newcastle in $1988 / 89$, which included relatively more young people among the controls than in the other two study groups. Younger people were more likely to be exposed to ETS and less likely to suffer a coronary event than older people; therefore, crude odds ratios tend to underestimate the true risk of a coronary event associated with exposure to ETS.

As in all epidemiological studies involving exposure to ETS, ascertainment of exposure is a possible source of bias. The effect of this form of bias is to make less clear the distinction between those exposed and those not exposed. In this study we dichotomised the exposure variable. However there is still likely to be some misclassification of exposure to ETS where the level of exposure is low, and this would tend to dilute the magnitude of any difference in risk. To assess the association between passive smoking and CHD more accurately, future studies need to use better methods of measuring exposure to ETS and attempts should be made to investigate dose-response relationships.

Another limitation of this study is the different way in which information was collected from cases and controls in Newcastle. Patients who died had questionnaires completed by relatives or other informants and patients who survived at least for some time in hospital were interviewed by study nurses, whereas controls completed a self-administered questionnaire. In Auckland questionnaires were administered by the study team to all controls, surviving patients, and informants for dead patients, and yet results were similar to those for Newcastle.

Yet another potential source of bias in studies of the effects of exposure to ETS is the misclassification of current smokers and former smokers as never-smokers. In this study no steps were taken to validate responses to questions on smoking status, and, although this would have been desirable, it is unlikely that the magnitude of any misclassification problem is such that an inflated risk would have been consistent over three separate data sets from two different countries and three time periods. The most likely cause of misclassification of smokers is due to former smokers being classified as never-smokers. We grouped together never-smokers and former smokers who had quit smoking at least 10 years ago because we believed they had similar risks of coronary heart disease; therefore, it is unlikely that our results were affected by this form of misclassification.

Whether women have an increased risk due to increased dose or other factors is not settled 
by this study, but more and more studies are indicating that there are harmful effects due to exposure to ETS. Reduction in prevalence of smoking (through education, taxation, and regulation) can reduce CHD through reducing risk due to fewer active smokers and through reducing exposure to ETS.

\section{Addendum}

Authoritative literature reviews, published since the final version of our paper was accepted for publication, concluded that there is a $30 \%$ increased risk of CHD associated with exposure to ETS at age 65 years. ${ }^{12}{ }^{13}$ Further analyses by Law et al, taking into account potential biases and confounding factors, concluded that exposure to ETS caused a $25 \%$ increase in risk of $\mathrm{CHD}$ at age 65 years. $^{12}$

These studies have been supported by the Health Research Council of New Zealand, the National Heart Foundation of New Zealand, the National Health and Medical Research Council, the National Heart Foundation of Australia, the Commonwealth Department of Human Services and Health, and Healthway. We are grateful to the Health Departments and Registrars General of Births, Deaths, and Marriages of New Zealand and New South Wales, the Australian Bureau of Statistics, and local hospitals and medical practitioners for assistance with various aspects of the studies. The authors would like to thank Hilary Alexander and Paula Steel for their contribution to the project.
1 Steenland K. Passive smoking and the risk of heart disease. 7AMA 1992;267:94-9.

2 Glantz SA, Parmley Ww. Passive smoking and heart disease, mechanisms and risk. $f A M A$ 1995;273:1047-53. 3 Dobson AJ, Alexander HM, Heller RF, et al. Passive smoking and the risk of heart attack or coronary death. Med $\mathcal{F}$ Aust 1991;154:793-7.

4 Tunstall-Pedoe H, Kuulasmaa K, Amouyel P, et al. for the WHO MONICA Project. Myocardial infarction and coronary deaths in the World Health Organisation MONICA Project. Circulation 1994;90:583-612.

5 Dobson AJ, Alexander HM, Heller RF, et al. How soon after quitting smoking does risk of heart attack decline? 7 Clin Epidemiol 1991;44:1247-53.

6 Kawachi I, Colditz GA, Speizer FE, et al. A prospective study of passive smoking and coronary heart disease. Cirstudy of passive smoking
culation 1997;95:2374-9.

7 Rosenberg I, Kaufman DW, Helmrich SP, et al. The risk of myocardial infarction after quitting smoking in men under 55 years of age. N Engl F Med 1985;313:1511-14.

8 Rosenberg I, Palmer JR, Shapiro S. Decline in the risk of Rosenberg I, Palmer JR, Shapiro S. Decline in the risk of
myocardial infarction among women who stop smoking. $N$ Engl f Med 1990;322:213-17.

$9 \mathrm{He}$ Y, Lam TH, Li LS, et al. Passive smoking at work as a risk factor for coronary heart disease in Chinese women who have never smoked. BMF 1994;308:380-4.

10 National Health and Medical Research Council of Australia. The health effects of passive smoking. Canberra: NHMRCA, 1997.

11 US Department of Health and Human Services. The health consequences of smoking: cardiovascular disease. A report of the Surgeon General, 1983. Rockville, Maryland: Public Health Service, Office on Smoking and Health, 1983. (DHHS Publication No (PHS) 84-50204.)

12 Law MR, Morris JK, Wald NJ. Environmental tobacco smoke exposure and ischaemic heart disease: an evaluation of the evidence. BMf 1997;315:973-80.

13 California Environmental Protection Agency, Office of Environmental Health Hazard Assessment. Health effects of exposure to environmental tobacco smoke. Sacramento: California Environmental Protection Agency, September 1997. <http:/ /www.calepa.cahwnet.gov/oehha/docs/finalets.htm> 